\title{
Leonardo da Vinci and his contribution to our understanding of the lumbosacral plexus
}

\author{
Rabjot Rai $^{1} \cdot$ Marios Loukas $^{1} \cdot$ R. Shane Tubbs ${ }^{1,2}$
}

Received: 15 July 2018 / Accepted: 18 July 2018 / Published online: 27 July 2018

(C) Springer-Verlag GmbH Germany, part of Springer Nature 2018

Leonardo da Vinci (1452-1519) (Fig. 1 and cover) was a master of many things including anatomy $[1,2]$. Moreover, he drew and described many neuroanatomical structures with details that had not been seen before his day [1-3].

During da Vinci's representations, he was able to masterfully decipher the complexity of such things as the brachial plexus displaying the divisions that form the upper, middle, and lower trunks [1]. His portrayal of the sympathetic trunk was one of the earliest. Initially, during his earlier neurological studies in Milan, he attempted to trace the peripheral nerves supplying the lower extremities; unfortunately, he neglected the area below the kidneys. However, he revisited the area and successfully delineated the essential components of the lumbosacral plexus, which he noted, "there are as many nerves as muscles in the thigh" [1]. He noted that the femoral nerve supplied the anterior thigh muscles, and that the obturator nerve was formed by three lumbar spinal nerves that passed through the obturator foramen to innervate the medial thigh muscles and overlying skin. He demonstrated the lateral femoral cutaneous nerve exiting superior to the pelvic bone and supplying the skin of the anterolateral thigh [1].

Alongside his drawing of the lumbosacral plexus, he wrote, "cut the tail (coccyx) through the middle just as you did the neck in order to see how the nerves of the spinal cord arise" [1] although there are inconsistencies with some of his depictions as, for example, the sciatic nerve is duplicated.

R. Shane Tubbs

shanet@seattlesciencefoundation.org

1 Department of Anatomical Sciences, St. George's University, St. George's, West Indies, Grenada

2 Seattle Science Foundation, 550 17th Ave, James Tower, Suite 600, Seattle, WA 98122, USA
Even without imaging modalities, da Vinci possessed the talent to precisely and accurately portray the vertebral column [3]. Unfortunately, most of da Vinci's work was unpublished, and thus, his brilliant records were not appreciated in the scientific literature of his day [2]. However, today, his accomplishments in neuroanatomy continue to be recognized $[4,5]$.

\section{Compliance with ethical standards}

Conflict of interest The authors have nothing to disclose.

\section{References}

1. Todd EM (1983) The neuroanatomy of Leonardo da Vinci. Capra Press, Santa Barbara

2. Bowen G, Gonzales J, Iwanaga J, Fisahn C, Loukas M, Oskouian RJ, Tubbs RS (2017) Leonardo da Vinci (1452-1519) and his depictions of the human spine. Childs Nerv Syst 33:2067-2070. https://doi.org/ 10.1007/s00381-017-3354-9

3. Naderi S, Andalker N, Benzel EC (2007) History of spine biomechanics: part II -from the renaissance to the 20th century. Neurosurgery 60:392-404. https://doi.org/10.1227/01.NEU.00002. 49263.80579.F9

4. Chaves H, Bendersky M, Goñi R, Gómez C, Carnevale M, Cejas C (2018) Lumbosacral Plexus root thickening: establishing normal root dimensions using magnetic resonance neurography. Clin Anat. https://doi.org/10.1002/ca.23073

5. Mahan MA, Sanders LE, Guan J, Dailey AT, Taylor W, Morton DA (2017) Anatomy of psoas muscle innervation: cadaveric study. Clin Anat 30:479-486. https://doi.org/10.1002/ca.22879 
Fig. 1 and cover Drawing from da Vinci's Notebooks depicting the lumbosacral plexus (left); Drawing of da Vinci (middle); and anterior view of the lumbosacral plexus with connections to the spinal cord (right)

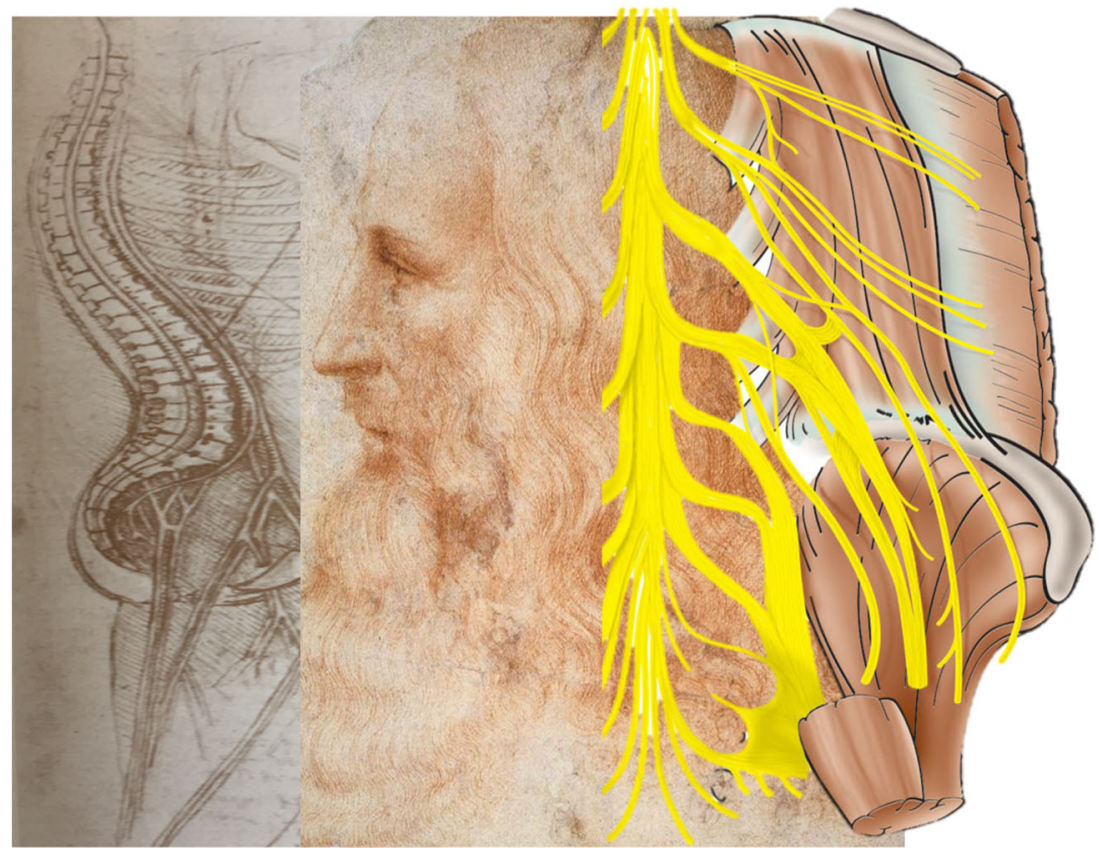

